\title{
Bride Price Syndrome and Dominance in Marriage: An Expository Analysis
}

\author{
FALANA Titi. C (PhD.)* \\ Department of Philosophy, Ekiti State University, Ado Ekiti, Ekiti State, Nigeria
}

*Corresponding Author: FALANA Titi. C (PhD.), Department of Philosophy, Ekiti State University, Ado Ekiti, Ekiti State, Nigeria

\begin{abstract}
Bride Price is that first and compulsory payment either in cash or in kind that a man pays to the parents of a girl or lady he intends marrying in order to be granted permanent traditional legitimate relationship with the girl, which will in turn bring about his own family. There are some cultural values attached to bride price that made the practice very significant; it serves as a gesture of sincerity, a symbol of faithfulness to the marriage, which is similar to the wedding and engagement rings used today. In lieu of the religious value added to it, there is a spiritual bond that the woman values to it. In our modern society however, bride price payment has become a very serious gender issue with implications on gender relations in different socio-cultural contexts and as such, it has brought about syndromes and dominance as the culprit to gender inequality and equity in marriages, manifesting itself as male dominance, loss of groom 's power, right and freedom in marriages. The simple logic behind this polemic is that the concept of bride price right from ab initio introduced commerce into the concept of marriage for it creates a situation whereby a commodity is bought and sold. Hence, this makes marriage for the female folk who is at the receiving end a pledge of perpetual servitude. Consequently, the researcher employs the expository analytic method to critically engage the concept and practice of bride price and its consequences in marriage. Based on the findings accruing from this expository excursus, the work argues that the concept of bride price in itself is not a bad practice. Rather what corrupt the concept and practice of bride price is cultural lore instigated by patriarchal stereotypes. Hence, the paper suggests that those cultural values that made bride price significant, should be reconsidered and that proper orientation should be given to those intending to marry in order to curb the problems of bride price in our modern society. The paper further suggests both families of the intending couple, should dialogue and both mutually foot the bill that native law and custom regarding marriage prescribes.
\end{abstract}

Keywords: bride price, dominance, gender, marriage, and syndrome

\section{INTRODUCTION}

It cannot be disavowed that Bride price is an obligatory payment made by a groom to the family from whom he takes a daughter in marriage. This payment of bride price also is widespread in many parts of the world though based on custom, tradition and religion. A potential husband, customarily with the support of his family, provides a significant amount of money or livestock or some highly valued goods to his prospective wife's family before a marriage can be contracted or as Oguli puts it "typically, bride price consists of contract where material items (often cattle, pig, or other animals) or money are paid by the groom to the bride's family in exchange for the bride for the labour and her capacity to produce children" . The practice of bride price is used to validate customary marriages and is mostly common in Africa countries especially Nigeria though different names have been allotted to it due to the multi-lingual nature of the nation. However, this practice of bride price payment is distinct from dowry that is evident in the Indians marital customs or traditions. Dowry payment is the opposite of bride price payment. It is a practice in which a bride's family pays money or some significant properties to a bride or bride's family at the beginning of marriage.

The practice of the payment of bride price before now has been a unique one in marriage because it serves as a starting point of the union of spouses. But in our present age, it has brought about serious

${ }^{1}$ Oguli, Oumo. Bride Price and Violence Against Women: the Case of Uganda, paper presented at the International Bride Price Conference, Kampala, Uganda (February, 2004) 
unhealthy gender based issues in marriages especially gender violence as well as dominance. Consequently, this paper sets to give an expository analysis of bride price syndrome and dominance in marriage. To achieve this, we shall be giving conceptual analysis of some terms like; bride price, marriage, syndrome and dominance, we shall equally give the nature and historical trace of bride price, and finally, we shall give some recommendations in order to put an end to the perceived syndrome and dominance.

\section{Conceptual Clarifications}

In keeping with the Aristotelian dictum: "Ab initio disputandis definitio nominis" (at the beginning of any discussion, define your terms), definition of terms especially in a work like this is inescapable. Hence, we shall define some of the key terms that are found in our topic of discussion.

\subsection{Bride Price}

It is the amount of money, property or other forms of wealth paid by a groom or his family to the parents of the woman he has just married or is just about to marry. However, the concept of brideprice has been conceptualized by many scholars and writers of marriage payments. For instance, bride price according to Sambe, Avanger, et. al, "is the payment made in kind, cash or material as demanded by custom of a group by a groom or his family to the family of the bride who in order to make the union legitimate"2. The tradition of bride price involves payment from a particular family to another, usually from the groom's family to the bride's family. In a case where the groom's family is not available, the groom handles the responsibility alone but in the company of other relative and friends. To this, Rakhimdinova in Sambe, Avanger, et. al., opined that it is "the amount of money or property or wealth paid by the groom or his family, to the parents of the woman upon marriage of their daughter to the groom"3. The bride price may not necessarily involve only money, sometimes the payment is done in a ceremonial form and other properties may also be presented to the bride's family in order to reflect the value of the girl or lady to be married.

Generally, the payment of bride price marks the beginning of any marriage. It makes a marriage to be legal, and to show the legitimacy of children, as bearing children out of wedlock especially in the African society is a taboo. Thus, one can rightly say that bride price is that first and compulsory payment either in cash or in kind, a man pays to the parent of a girl or lady he intends marrying in order to gain access to a relationship with the girl, which will in turn bring about his own family. It is that first and compulsory payment either in cash or in kind that a man pays to the parent of a girl or lady he intends marrying in order to gain access to a relationship with the girl, which will in turn bring about his own family. There are some cultural values attached to bride price that made the practice very significant, such as; serves as a gesture of sincerity, a symbol of faithfulness to the marriage, which is similar to the wedding and engagement rings used today; because of the religious value added to it, there is a spiritual bond that the woman values to it. In our modern society however, bride price payment has become a very serious gender issue with implications on gender relations in different socio-cultural contexts and as such, it has brought about syndromes and dominance as the culprit to gender equality and equity in marriages, manifesting itself as male dominance, loss of bride's power, right and freedom in marriages. It has been the case that because it is men (grooms) who make the payment of bride price, majority often use that as an avenue to infringe on the right as well as freedom of the female gender thereby placing the females in an unequal level with the males.

\subsection{Marriage}

Marriage is "a legally recognized relationship, established by a civil or religious ceremony, between two people who intend to live together as sexual and domestic partners". ${ }^{4}$ It is the union between a man and woman. This definition has been advanced by scholars. For instance, Westermarck in Sambe, Avanger, et. al. defined marriage as "a more or less durable connection between male and female lasting beyond the mere act of propagation till after the birth of the offspring" ${ }^{\text {. Sambe, }}$ Avanger, et. al. went further to define marriage as "a relationship of one or more men to one or more

\footnotetext{
${ }^{2}$ Sambe, N., Avanger M., et. al. "The Effects Of High Bride-Price On Marital Stability": IOSR Journal Of Humanities And Social Science (IOSR-JHSS), Volume 17, Issue 5 (Nov. - Dec. 2013), PP 65-70

${ }^{3}$ Ibid.

${ }^{4}$ Encarta Dictionaries

${ }^{5}$ Sambe, N., Avanger, M., et. al. "The Effects Of High Bride-Price On Marital Stability": IOSR Journal Of Humanities And Social Science (IOSR-JHSS), Volume 17, Issue 5 (Nov. - Dec. 2013), PP 65-70
} 
women that is recognized by law or custom". ${ }^{6}$ The salient fact epitomized in the above definition is that marriage is only permissible between complementary (opposite) sexes and this invariable eschews homosexual unions as marriage.

The above definition of marriage however, does not have a total support from other scholars because the nature of culture in one society may be different from another. Thus, Sambe, Avanger, et. al. went further to state that "...the union between man and women such that children born by the woman are the recognized offspring of both parents". ${ }^{7}$ This shows that in actual sense, children outside marriage can be considered illegal. To this, Fineman in M. M. Uzomah, defined marriage as "the legal union of a couple as a husband and wife. A contract based upon a voluntary private agreement by a man and a woman to become husband and wife. A voluntary union for life of one man and one woman to the exclusion of all other definition." ${ }^{8}$ With this, one can rightly say that marriage is a union between a man and woman after a legal agreement involving the payment of bride price and other religious rites, depending on the customs or traditions of a particular place.

\subsection{Syndrome}

This refers to a "group of identifying signs and symptoms - a group of signs and symptoms that together are characteristic or indicative of a specific disease or other disorder." ${ }^{9}$ It is "a recognizable pattern of signs, symptoms and or behaviors, especially of a specific disease or other disorder." ${ }^{10}$ The two definitions are pointing towards some particulars features involving syndrome, namely; signs and symptoms of a disease usually visible and indicating ill-health of an individual or animal.

However, conceptualizing syndrome in our topic of discussion, it could be seen as the visible, unusual and undesired happenings in marriages warranted by the payment of bride price. Gender disparity and dominance are good examples. Most men the world over feel that because they spent a fortune to acquire or purchase their wives that they have total control over them as they would have over their properties and material possessions. This brings to question the philosophical significance of bride price. This apparent psychological feeling and disposition known as syndrome eventually overtly and covertly gives rise to male dominance in marriage.

\subsection{Dominance}

The concept, dominance refers to the power exerted over others. It is a control or command wielded over others. It is a kind of supremacy and authority portrayed by an individual over others. Within the context of marriage and gender studies, dominance here refers to the supremacy a particular gender especially the male gender portrays or exerts over the female gender in marriage. It is a kind of syndrome that emanated from or after the payment of bride price. The dominance of male or husbands over their wives have caused some kind of gender disparity especially in Nigeria. An adverse effect of this may lead to all forms of gender based domestic violence against women.

\subsection{The Nature and Historical Root of Bride Price}

From the preceding excursus, it can be deduced that the essential features of bride price may be summarized as thus: it is a compulsory levy or payment, it may take the form of money, natural produce or some other form of property. The payment is made to the parent or guardian of the brideto-be on account of the marriage of the female person and it is paid in respect of a marriage which is intended or has taken place. Furthermore, the nature of bride price is not the same in all traditions because it can take the form of a gift or payment, depending on the customary law of each locality and culture. In time past, bride price took the form of labour provided by the suitor for the parents of his wife-to-be. Such labour was rendered in addition to a small cash payment and drinks. But with the advent of modern cash economy, bride price took the predominant form of money payment. At the same time, payment in other forms of property became a rare occurrence.

Consequently, Nambozo alluded that there are some cultural values attached to bride price. This is simply because bride price is rooted in culture. To this, Nambozo gave these cultural values as:

\footnotetext{
${ }^{6}$ Ibid.

${ }^{7}$ Ibid.

${ }^{8}$ M. M. Uzomah, Fundamental Issues in Gender Studies and Human Sexuality: the Philosophy of Gender

Parity, Ekpoma, Edo State, Nigeria: E-mesh Printing Press, p 306.

${ }^{9}$ Encarta Dictionaries

${ }^{10}$ wikidictionary
} 
Serves as a gesture of sincerity, a symbol of faithfulness to the marriage, which is similar to the wedding and engagement rings used today; because of the religious value added to it, there is a spiritual bond that the woman values to it. The Bride price provides a financial gain for the Bride's family in terms of gifts in cash and kind. A man will never be respected if he fails to pay bride price. A woman is expected to live under the dominance of her husband if bride price is paid. ${ }^{11}$

This Nambozo maintained, does not mean that the man will respect her. In many cases, he will own her as a piece of property. ${ }^{12}$ Furthermore, the payment of bride price is generally accepted and thus viewed as a practice intended to honour the bride and her family. This is considered to be a just practice because it was believed that the payment of bride price contributes to the firmness of the marriage. Hence, the higher the price paid, the higher the perceived honour it would have done the bride and her family. Another advantage the concept and praaactice of bride price is believed to have is that it is a factor that stabilizes and makes marriage durable. For instance, some problems in marriages that would have ordinarily led to separation of spouses can be resolved with the aid of the bride's family to ensure the stability of the union since they will need to refund the bride price if the relationship fails. Furthermore, bride price was also seen as the strength of marriage because it brings together the families leading to acceptance. It confirms the beginning of union which started with love. Also, it is argued that it is given on the basis that the wealth received compensates the bride's family for time, money and trouble taken to raise a daughter who is later sent off to live with another family. ${ }^{13}$ Bride price is a sign of fulfillment of a customary marriage giving assurance and confidence to the parties involved. It also shows that the man has the well without to maintain a lady and family responsibility.

Be that as it may, it is important to note that bride price is not just a new practice of our time. The practice of bride price dates back as far as 3000 BCE. Quale notes that "the ancient civilizations of Egyptians, Mesopotamians, Hebrews, Aztecs, and Incas all used bride price." ${ }^{\prime 4}$ Hughes went further to stating that "the Germanic tribes, who date from 2000 BCE and ruled western Europe from the 600 to $1000 \mathrm{CE}$, required bride price for a marriage to be legal." 15 As such, a valid marriage contract in Islamic law required a form of bride-price for it to be legal. Such transactions are associated with the Maghreb of the early Middle Ages, Bedouin tribes of the Middle East, and countries previously under the Ottoman Empire such as Iraq, Syria, Egypt, Turkey, Iran, Albania, and Afghanistan. ${ }^{16}$ Classical China required the negotiation of a bride price for the validity of marriage, and these transfers continue to be the norm in many rural areas today. China also seems to be one of the few examples where bride price and dowry coexist, with the bride price being compulsory and the dowry, which is more voluntary in nature, typically financed with a return portion of the bride price. Taiwan also seems to follow this traditional Chinese practice of exchanging marriage payments in both directions. Other countries in Southeast Asia, such as Thailand, Indonesia, and Burma, seem to only transfer bride prices. ${ }^{17}$

The payment of bride price has also been an important integral part of marriage rites and ceremonies in African culture. The payments are most prevalent in Africa; more than 90 percent of sub-Saharan societies traditionally made such marriage payments. ${ }^{18}$ Also, bride price is a well-established principle of customary law in Nigeria that the payment of bride price is an essential ingredient of a valid customary law marriage. Though, the term 'bride price' is often used interchangeably in some parts of Nigeria with 'dowry' by both writers and others concerned with customary law. Such practice, however, may lead to confusion in thought as 'dowry' strictly means the property which a woman

\footnotetext{
${ }^{11}$ Nambozo, B. Religious and Cultural Perspectives on Bride Price: "Bride Price Conference, MIFUMI", 104.1 Power FM Kampala

${ }^{12}$ Ibid

${ }^{13}$ Ibid

${ }^{14}$ Quale, R.G. A History of Marriage Systems. New York: Greenwood Press, 1988, p. 5

${ }^{15}$ Hughes, D. O. "From Brideprice to Dowry in Mediterranean Europe"; In The Marriage Bargain: Women and Dowries in European History. New York: Havorth Press, 1985. Pp.13-58

${ }^{16}$ Ibid.

${ }^{17}$ Sambe, N., Avanger, M., et. al. "The Effects Of High Bride-Price On Marital Stability": IOSR Journal Of Humanities And Social Science (IOSR-JHSS), Volume 17, Issue 5 (Nov. - Dec. 2013), PP 65-70

${ }^{18}$ Goody, J. and Stanley T. Bride Wealth and Dowry in Africa and Eurasia, Cambridge: Cambridge University Press, 1973, PP 1-58.
} 
brings to her husband. While bride price is any gift or payment, in money, natural produce, brass rods, and cowries or in any other kind of property whatsoever, to a parent or guardian of a female person on account of a marriage of that person, which is intended or has taken place. ${ }^{19}$

Just as the payment of bride price plays a very important role in the marriages of Africans as well as Nigerians, it has been used as a gateway by most men to bring about gender disparities. Hence, in the following, we shall examine the syndromes and dominance in marriages as caused by the payment of bride price.

\section{BRIDE PRICE SYNDROME AND DominanCe In MARRIAGE}

Bride price syndrome and dominance in marriage refers to those undesirable issues happening in marriages. They can be described as the effects of bride price in marriages of today. Bride price payment has brought about implications on gender relations, values roles and expectations in different socio-cultural contexts and impacts Sexual and Reproductive Health and Rights. To this, one can rightly say that bride price has lost its value or primary significance in the modern time. It has become the infamous catalyst of women's denigration and perpetual servitude and subjugation in marriage and family life.

Consequently, its syndrome and dominance can be analyzed in form of domestic violence seen in the following:

\subsection{Men are Dominant in Decision-Making}

Here; woman has no power for anything. Where the man is doubtful or insecure, domestic violence is common. This is mostly where the man is jobless or the woman has advanced training and social status, he expects the woman to show him respect as the village women should. ${ }^{20}$ As such, the woman has no opinion over any matter. President Mohamadu Buhari's statement about his wife is a good example male dominance - he made her to understand that she has no say over any other issue apart from those bothering on the kitchen (the other room).

\subsection{Women Lack Power to Make Decisions in the Home}

Similar to the point above is the fact that culture does not allow women to stand up to the men. The laws are also support men, especially over sexual matters. Some women did not want to have sex with the spouses, yet the men demanded for it. But since many may not want sex yet their men want, they have nothing to do but accept, or else the men will force them. The men may not accept any reasons after all; they think it is their right at any time. ${ }^{21}$ Having paid bride price is perceived by some men as implying absolute rights over the woman. This affects negotiation of use of contraceptives or preventive measures for sexually transmitted infection, as reported by one respondent:

Men and women don't have equal power to decide. Men have overall power after paying for the wife. This is worse where the men are violent to spouses. If the woman insists on condom use, (this) raises suspicion of sexually transmitted infections. They (women) can never decide on their own, even in situations where their health is at risk. Often they can't report injuries they suffer. They can miscarry or even die (of injuries). ${ }^{22}$

\subsection{Gender Economic Inequality}

This is the belief that women are not in any position or has no right to handle money. Thus, the payment of bride price in many cultural contexts relates to the above factor through perpetuating economic inequality. Women in many families were dependent on economic support from men. Since the perception was that women were bought, the buyers (grooms) controlled all financial and social resources (the wife inclusive). This reduces the woman's decision-making, enhancing gender power imbalances. Such women feared leaving an abusive relationship as the man may demand repayment of bride price by her family.

\footnotetext{
${ }^{19} \mathrm{https} / / /$ nigerianobservernews.com/2015/08/without-bride-price-there-is-no-marriage/ retrieved $2^{\text {nd }}$ November, 2018

${ }^{20}$ Heise L. "Violence Against Women: An Integrated Ecological Framework". Sage Journals, 1998; 4: $262-290$. ${ }^{21}$ Ibid.

${ }^{22}$ Silberschmidt, M. "Rethinking men and gender relations: an investigation of men, their changing roles within the household and implication for gender relations in Kisii District, Kenya". CDR Research report No. 16
} 


\subsection{It Reduces Women's Decision-Making about Reproductive Health}

Having no economic power; women were perceived to be at a disadvantage in negotiating sexual relations. Consequent upon non-negotiation, high fertility rates, low contraceptive use rates and poor health of women were perceived to be related to bride price payment. ${ }^{23}$ This has caused frequent pregnancies, as the men may not allow women to use contraceptives suspecting that they may end up being promiscuous. The men get insecure if women start using contraceptives, especially for women who have some work outside the home.

Bride price syndrome and dominance brings about gender issues that affects the broad context of people's lives as it influences what roles are considered appropriate. Where bride price payment reduces the power and prestige of the woman, the perception that the woman was paid for, belongs to the man and has less household decision-making power is a manifestation and the basis or consequence of gender inequality. Repayment of bride price creates divorce restrictions. Fear of stigma, social vulnerability and lack of financial independence may keep women in such relationships. Landenburger describes a complex process of coping with violence occurring in 4 stages. In the binding stage, there is rationalization or denial, where women focus on the positive aspects of the relationship. In the enduring stage, there is shift in perception: cover up, self-blame and behaviour modification. In the disengagement stage, there is help seeking, while the recovery stage is marked by leaving. Gender inequality maintains the entrapment and complex coping process. ${ }^{24}$

In addition, the demand for the refund of bride price by men in some cultures or traditions, when a marriage breaks down, raises the problem of inequality between the partners in the marriage. When a woman wants to leave an abusive relationship or the man asks her to leave, she must first refund the money paid for her. This forces many women to remain in the marriage and endure violence and abuse. Demanding refund of bride price does not take into account the contribution of the woman to the marriage, the children she has produced and the productivity of her labour.

In as much as bride price syndrome and dominance is evident in the society today, the bride's family has also contributed. There are families that bargain and as well, place bride price to be so high as if they are selling their daughter out. They demand for high payment from the groom or groom's family as if the groom has made a mistake for loving their daughter to the point of marriage. This alone has giving some men the impression that they are possessing items or properties in the market, so that they can treat them (wives) the way they feel, without remorse or conscience. Some of these syndromes and dominance seen in marriages are caused by ignorance. While, some are due to temperaments - an individual difference and as a result of bad training some men received from their parents regarding respect to human right and person especially women. Most times, this is seen in rich families - a man coming from a rich family may have a kind of I don't care attitude regarding the way he treats his wife.

\section{CONCLUSION}

From the ongoing discussion, it has been made clear that bride price was primarily meant to play positive cultural impact in families as well as marriages, such as; creating instability in marriage, to bring about prestige and acceptance in various communities of the parties to the marriage. It brings about honour and recognition to the family of the woman. It makes a marriage to be formal and legal and brings about legitimate children.

In our modern society however, bride price has increasingly become a tool of oppression of married women and as such, a means of gender disparity in the society. It has become a severe syndrome that has brought about dominance of males (husbands) over the females (wives). Women remain in marital relationship where they are not respected and are treated badly especially in cultures where divorcing a man will warrant the woman or her family refunding the bride price they have received from the man and where it cannot be afforded, she cannot marry again and even if she marries and beget children, those children will be claimed by the former husband or as the custom and tradition of place demands. The concept and practice of bride price as it is in our day today objectifies women folks and makes them domestic slaves and victims of varying degrees of gender based domestic violence and vices.

\footnotetext{
${ }^{23}$ Heise L. "Violence Against Women: An Integrated Ecological Framework". Sage Journals, 1998; 4: $262-290$.

${ }^{24} \mathrm{https} / / / \mathrm{www}$.onlinenigeria.com/marriages-in-nigeria/Bride-Price/ retrieved $2^{\text {nd }}$ November, 2018
} 
Consequent upon the above evident analysis, the question remains; should we abolish the practice of bride price payment? If yes, another question is; since there are some individual differences attached to these problems, will marriages be in peace if the practice of bride price is abolished? Then if no to the former or later question, another important question is; what can we do to prevent the reoccurrence of these problems in marriages? Can this cultural phenomenon be reserved to give way to groom price? These questions will then lead us to recommendations.

\section{RECOMMENDATIONS}

The practice of the payment of bride price should not be abolished since it is the prerequisite for a legal marriage. Rather, we should return to the traditional aim (as mentioned earlier) in which it was established. Consequently, the following should be encouraged:

\section{i. Marital Institutions}

There should be the establishment and encouragement of marital institutions where orientation would be given to intending spouses on how to respect one another. Here, they should also be taught on how to be in peace and dialogue among themselves before taking decisions. These institutions can begin from parents teaching their children who wish to marry how to appreciate one another, with practical examples since they have experience in marriage. To ensure all these, cultures and religions can as well give orientations to those intending to marry. The premarital course established by the Roman Catholic Church should be encouraged and emulated by other religious sects. Furthermore, a marital course should be inculcated into educational curriculum - where all students before diving to their major field of study, would appreciate marital life when faced with the reality of marriage.

\section{ii. Marriage Conferences}

Professionals in this area of life should always set up conferences for those intending to marry and those who are already married. Here, a proper orientation and reorientation should be given to spouses and those intending to marry. They should equally be taught the ways in which they can maintain peaceful relationships in their marriage and how to settle their differences without resulting to gender inequality.

\section{iii. Discontinuation of Bride Price Escalation}

The culture of increasing bride price should be abolished. As such, grooms should be made to realize that their wives are not sold to them hence, if they are not treasured and treated humanely, they will have no other option than to discontinue that relationship.

\section{iv. Discontinuation of Bride Price Bargain}

Families should stop bargaining bride price as if they are selling properties. It has been the case that some bride's families especially in Nigeria bargain bride price with their in-laws. This bargain is as a result of escalation of the price as they intend to enrich themselves or gain what they think they have spent at the process of training the brides from birth to adulthood.

\section{v. Discontinuation of Bride Price Refund}

The practice of refunding bride price before dissolving ill-health marriages in some cultures should be abolished so that even if a brides family has no money, their daughter can quit the marriage when she could no longer bear maltreatment.

\section{vi. Practicability of the Constitution Regarding Human rights}

The prescriptions of the constitution regarding respect for human rights should be adhered and as such, punishment should be given to any man found guilty. This will bring the understanding that both men and women have the right to marry, to equal rights in marriage, during marriage and at its dissolution.

\section{vii. Dialogue Between both Families on who Pays}

Since bride price payment has brought about many issues in marriages, both families can as well come together to dialogue and agree on who pays the price, either the bride's family (bride price) or the grooms family (groom price). This can only be actualize through the understanding that it not the money or the material things involved in the payment that makes marriages firm, but love - love that 
brings about the support of one another. Again, groom's price can only work especially in our continent if only families and men will through away their pride - the pride that makes them think they are less-men if the bride or bride's family pays the price before their marriage.

All things been equal, it is expected that all of the above will bring about the following in marriages and families:

- The Respect for human person and rights.

- The Value for each other.

- The understanding between husband and wife.

- Men will learn to treasure their wives.

- Gender related issues will be put to an end.

- There would not be bride price syndrome and dominance any more.

\section{REFERENCES}

[1] Encarta Dictionaries

[2] Goody, J. and Stanley T. Bridewealth and Dowry in Africa and Eurasia, Cambridge: CambridgeUniversity Press, (1973)

[3] Hughes, D. O. "From Brideprice to Dowry in Mediterranean Europe"; In The Marriage Bargain: Women and Dowries in European History. New York: Havorth Press (1985)

[4] Heise L. "Violence Against Women: An Integrated Ecological Framework". Sage Journals (1998)

[5] https://nigerianobservernews.com/2015/08/without-bride-price-there-is-no-marriage/retrieved $2^{\text {nd }}$ November, 2018

[6] https://www.onlinenigeria.com/marriages-in-nigeria/Bride-Price/ retrieved $2^{\text {nd }}$ November, 2018

[7] Kaplan, Marion A. "Women and Dowries in European History", New York: Havorth Press (2016)

[8] M. M. Uzomah, Fundamental Issues in Gender Studies and Human Sexuality: the Philosophy ofGender Parity, $1^{\text {st }}$ ed, E-mesh Printing Press, Ekpoma, Edo State, Nigeria (2017)

[9] Nambozo, B. Religious and Cultural Perspectives on Bride Price: "Bride Price Conference, MIFUMI", 104.1 Power FM Kampala (2004)

[10] OguliOumo, M. Bride Price and Violence Against Women: the Case of Uganda, paper presented at the International Bride Price Conference, Kampala, Uganda (February, 2004)

[11] Quale, R.G. A History of Marriage Systems, New York: Greenwood Press (1988)

[12] Silberschmidt, M. CDR Research report No. 16. Copenhagen: "Rethinking men and gender relations: an investigation of men, their changing roles within the household and implication for gender relations in Kisii District", Kenya (1991).

[13] Sambe, N., Avanger, M., et. al. "The Effects Of High Bride-Price On Marital Stability": IOSR Journal Of Humanities And Social Science (IOSR-JHSS), Volume 17, Issue 5 (Nov. - Dec. 2013)

[14] Wiktionary mobile edition.

\section{AUTHOR'S BIOGRAPHY}

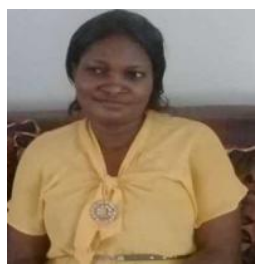

Dr. Mrs. T. C. Falana is a Senior Lecturer in the department of Philosophy, Ekiti State University, Ado Ekiti, Her research interest extends over a wide range of philosophical issues with special focus on applied ethics and gender studies. She has attended conferences both at local and international levels. She is a prolific writer.

Citation: FALANA Titi. C. "Bride Price Syndrome and Dominance in Marriage: An Expository Analysis". International Journal of Humanities Social Sciences and Education (IJHSSE), vol. 6, no.8, 2019, pp. 132-139. doi: http://dx.doi.org/10.20431/2349-0381.060811.

Copyright: (C) 2019 Authors. This is an open-access article distributed under the terms of the Creative Commons Attribution License, which permits unrestricted use, distribution, and reproduction in any medium, provided the original author and source are credited. 